\title{
Identification of Novel Steroidal Androgen Receptor Degrading Agents Inspired by Galeterone $3 \boldsymbol{\beta}$-Imidazole Carbamate
}

\author{
Puranik Purushottamachar, ${ }^{\dagger,}$ Andrew K. Kwegyir-Afful, ${ }^{\dagger, \$}$ Marlena S. Martin, ${ }^{\dagger,+, \S}$
}

Vidya P. Ramamurthy, ${ }^{\dagger, \ddagger}$ Senthilmurugan Ramalingam, ${ }^{\dagger, \hbar}$ and Vincent C. O. Njar ${ }^{*},+,, \|$

${ }^{\dagger}$ Department of Pharmacology, ${ }^{\ddagger}$ Center for Biomolecular Therapeutics, and ${ }^{\|}$Marlene Stewart Greenbaum Cancer Center, University of Maryland School of Medicine, 685 West Baltimore Street, Baltimore, Maryland 21201-1559, United States

Supporting Information

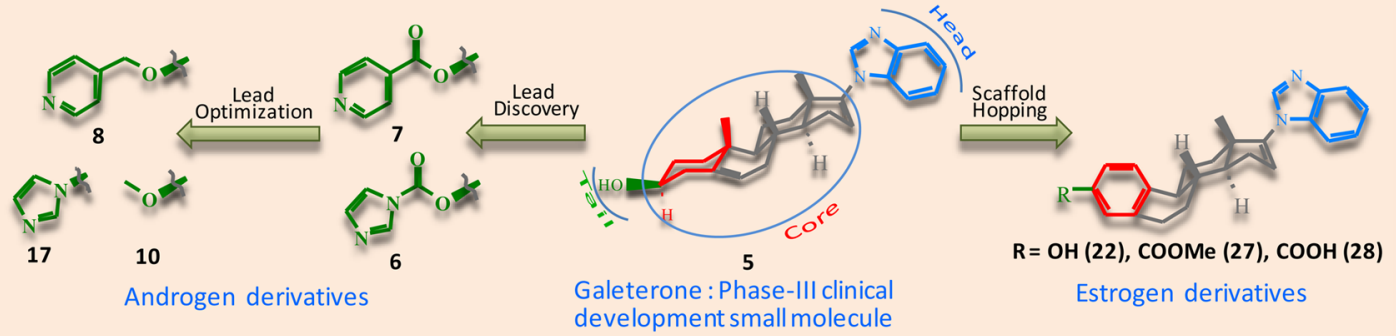

ABSTRACT: Degradation of all forms of androgen receptors (ARs) is emerging as an advantageous therapeutic paradigm for the effective treatment of prostate cancer. In continuation of our program to identify and develop improved efficacious novel small-molecule agents designed to disrupt AR signaling through enhanced AR degradation, we have designed, synthesized, and evaluated novel C-3 modified analogues of our phase 3 clinical agent, galeterone (5). Concerns of potential in vivo stability of our recently discovered more efficacious galeterone $3 \beta$-imidazole carbamate (6) led to the design and synthesis of new steroidal compounds. Two of the 11 compounds, $3 \beta$-pyridyl ether (8) and $3 \beta$-imidazole (17) with antiproliferative $\mathrm{GI}_{50}$ values of 3.24 and $2.54 \mu \mathrm{M}$ against CWR22Rv1 prostate cancer cell, are 2.75- and 3.5-fold superior to 5. In addition, compounds 8 and 17 possess improved ( 4-fold) AR-V7 degrading activities. Importantly, these two compounds are expected to be metabolically stable, making them suitable for further development as new therapeutics against all forms of prostate cancer.

KEYWORDS: Androgen receptor (AR), splice variant $A R(A R-V 7)$, androgen receptor degrading agents (ARDAs), prostate cancer

G lobally, prostate cancer (PC) is the second most commonly diagnosed human cancer in men, accounting for 260,000 deaths yearly. ${ }^{1}$ Almost $80 \%$ of cases are diagnosed as localized disease, and radiation or surgery can be curative. However, despite current treatment options, there is still a relapse rate of $30-60 \%{ }^{1}$

Androgens and androgen receptor (AR) play crucial roles in the development and progression of $\mathrm{PC}$, $^{2,3}$ As a consequence, for locally advanced or metastatic disease, hormonal treatment with androgen deprivation therapy, which blocks the production (CYP17 inhibitors: abiraterone; 1) ${ }^{4}$ and/or activity of androgen (antiandrogens, bicalutamide; 2$)^{5}$ (Figure 1), is a standard approach for the majority of patients, but, for most cases, the duration of response is limited to $12-24$ months, and the disease will become castration-resistant prostate cancer (CRPC) with no treatment options. ${ }^{6}$ Approximately $85 \%$ of CRPC patients die within 5 years and docetaxel (3) is currently the only treatment shown to provide even minimal survival benefit.'

In castration-resistant environment, aberrant $\mathrm{AR}$ reactivation is implicated through numerous mechanisms, which leads to overexpression of mutated AR, AR amplification, and local androgen synthesis. ${ }^{8-10}$ Recently, multiple alternative spliced

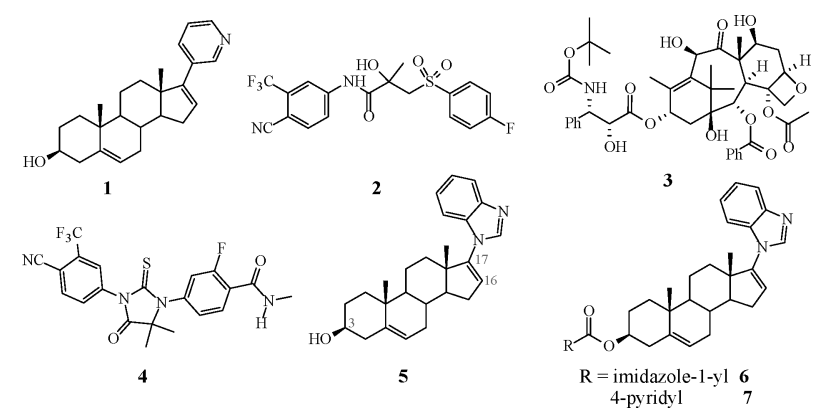

Figure 1. Chemical structures of compounds $\mathbf{1 - 5}$ (clinical anti-PC agents) and selective ARDAs (6-7).

AR isoforms (AR-Vs) have been identified in CRPC. ${ }^{11-14}$ Unlike full-length AR (fAR), AR-Vs lack the ligand-binding domain (LBD) and are androgen refractory. ${ }^{12,14}$ The AR-Vs are expressed at higher levels in various tumors and are 3- to 5-fold more potent than $\mathrm{f}-\mathrm{AR}$ in transactivating activity. ${ }^{15}$ It has

Received: April 1, 2016

Accepted: May 23, 2016

Published: May 23, 2016 
recently been clearly demonstrated that patients expressing constitutively active AR-Vs do not benefit from antiandrogens and therapies that inhibit androgen biosynthesis. ${ }^{16,17}$ In fact, not all CRPC patients respond to novel antiandrogen (enzalutamide; 4) or CYP17 inhibitors (1), and even those who do subsequently relapse within a few months. ${ }^{18-20}$ Based on these findings, we envision that effective treatment of CRPC patients will require new drugs that can modulate all forms of AR such as AR degrading/down-regulating agents (ARDAs). ${ }^{21,22}$ The substantial anti-PC efficacy of phase 3 development agent galeterone (Figure $1 ; 5$ ) in comparison to abiraterone $(\mathbf{1})^{23}$ or casodex $(\mathbf{2})^{24}$ may be attributed to galeterone's AR degrading (ARD) activity.

For the development of new ARDAs, we recently showed, using rational structure-activity relationship (SAR) studies that modifications of the C-3 hydroxyl, unlike modifications at C-16 and C-17 of galeterone (5), yield novel analogues (e.g., imidazole carbamate, 6 and pyridine carboxylate, 7) with enhanced $\mathrm{PC}$ antiproliferative and $\mathrm{AR}$ modulating ( $\mathrm{AR}$ antagonism and AR/AR-Vs degrading) activities. ${ }^{22}$ Mechanistic examination suggests that compounds 5 and $\mathbf{6}$ induce proteasomal degradation of AR/AR-V7, which involves complex formation with E3 ligases $\mathrm{Mdm} 2$ and CHIP (Cterminus of Hsp70-interacting protein) concomitant with enhanced ubiquitination. ${ }^{25}$

In recent antitumor efficacy studies, we showed that 6 was moderately more efficacious than galeterone (70 versus $60 \%$ growth inhibition, respectively, compared to control) in inhibiting the growth of CRPC CWR22Rv1 tumor xenografts. ${ }^{25}$ Although we are yet to conduct in vivo pharmacokinetics study of these lead ARDAs, the presence of metabolically labile functions such as carbamate and ester groups in compound 6 and 7, respectively, may be a matter of concern. Therefore, the present study aimed to develop novel ARDAs with metabolically stable chemical moieties tethered at C-3 of androstene and estrogen steroidal cores, but with retention of the $\mathrm{C}-17$ benzimidazole moiety.

Starting from previously identified 4-pyridylester (7) with potent ARD activity, ${ }^{22}$ we decided to keep the pyridyl ring fixed and modify the ester-link to obtain metabolically stable compounds. This modification also serves as probe for the role/significance of the ester moiety toward ARD activity. Considering the relative metabolic stability of ether function over ester, compounds 8 and 9 were designed. Similarly, to probe influence of the pyridyl ring toward ARD activity, the simple methyl (10) and benzyl (11) ethers were designed (Scheme 1).

These four C-3 ethers (8-11, Scheme 1) were prepared by following Williamson's etherification method of treating alcohol (5) with respective aryl/alkyl halide in the presence of sodium hydride as base in DMF with yields of $12,43,77$, and $87 \%$, respectively. Considering the potency of $\mathbf{6}$, we also prepared the thiocarbamate derivative 12,54.5\% yield (Scheme 1), by refluxing 5 and $1,1^{\prime}$-thiocarbonyldiimidazole in acetonitrile and dichloromethane. To probe the influence of C3 substituent the $\Delta^{3,5}$-diene (13), without any C3 substituent was obtained (13\% yield) by neat pyrolysis of $6^{22}$ at $195{ }^{\circ} \mathrm{C}$ (just above its $\mathrm{mp}$ ). ${ }^{26}$

In our previous investigation, an attempt to synthesize $3 \beta$ imidazole derivative of galeterone yielded C-3 imidazole carbamate $(6) .^{22}$ An attempt to synthesize $3 \beta$-imidazole derivative by refluxing $3 \beta$-mesyl compound $14,{ }^{22}$ with imidazole under anhydrous condition in toluene resulted in compounds 15 (35\%), 16 (3\%), and 17 (11\%) along with a
Scheme 1. Synthesis of Androstene Derivatives (8-13, 1517) ${ }^{a}$

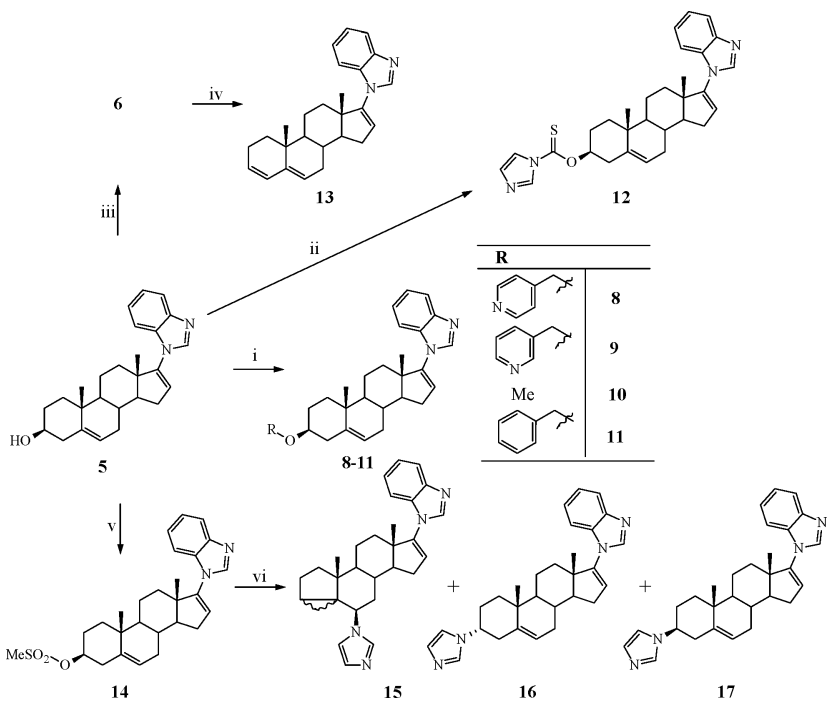

${ }^{a}$ Reagents and conditions: (i) NaH, DMF, R-X, rt or heat, 1-12 h; (ii) 1,1'-thiocarbonyldiimidazole, $\mathrm{CH}_{3} \mathrm{CN}$, DCM, reflux, $5 \mathrm{~h}$; (iii) $1,1^{\prime}$ carbonyldiimidazole, $\mathrm{CH}_{3} \mathrm{CN}$, rt, $2 \mathrm{~h}$; (iv) dry heat at $195^{\circ} \mathrm{C}, 1 \mathrm{~h}$; (v) mesyl chloride, pyridine, ice $(5 \mathrm{~h})$, then $\mathrm{rt}(5 \mathrm{~h})$; (vi) toluene, imidazole, reflux, overnight.

possible elimination product $\left(R_{\mathrm{f}}\right.$ value similar to 13 , not isolated) (Scheme 1). These three positional isomers were separated by preparative HPLC (see Supporting Information for method and chromatogram).

As an androstene core alternate, estrogen was selected, where three derivatives, including C-3 hydroxy (22), C-3 methylcarboxylate (27), and C-3 carboxy (28) were designed and synthesized (Scheme 2). Synthesis of these compounds was achieved by slightly modifying our routine method for synthesis for galeterone and related compounds. ${ }^{22}$

The synthesis of estrone-3-hydroxy-17-1H-benzimidazole compound (22, Scheme 2) started with 3-acetylation of estrone with acetic anhydride in pyridine to give $\mathbf{1 8}$ in $98 \%$ yield. Compound 18 was subjected to Vilsmeier-Haack reaction by treating with phosphorus tribromide in DMF and $\mathrm{CHCl}_{3}$ to give 16 -formy-17-bromo derivative 19 in $26 \%$ yield. An attempt to append a benzimidazole (BzIm) to $\mathrm{C}-17$ position of 19 following our routine $\mathrm{K}_{2} \mathrm{CO}_{3}$ in DMF method ${ }^{22,27}$ resulted into mixture of four compounds (partial 3-deacetylation with or without BzIm substitution, acetylated BzIm product and substrate). Therefore, we first hydrolyzed 3-acetyl group of 19 by treating with $10 \%$ ethanolic- $\mathrm{KOH}$ to obtain $20(28 \%)$. Thereafter, the BzIm group was appended using $\mathrm{K}_{2} \mathrm{CO}_{3}$ in DMF to give 21 in $84 \%$ yield and finally 16-deformylation by refluxing with $10 \% \mathrm{Pd} / \mathrm{C}$ in benzonitrile to obtain desired compound $\mathbf{2 2}$ in very low isolated $6 \%$ yield.

The synthesis of 17-benzimibazole estrone-3-carboxlate (28, Scheme 2) was initiated by activation of estrone via treatment with triflic anhydride in the presence of organic base (TEA) ${ }^{28}$ to give the corresponding triflate $\mathbf{2 3}$ in $\mathbf{3 7 . 4 \%}$ yield. Treatment of 23 with $\mathrm{Pd}$-catalyzed carbonylation using $\mathrm{Pd}(\mathrm{OAc})_{2}$ as catalyst, 1,c-bis(diphenylphospheno)propane as the phosphine ligand, in the presence of gaseous carbon monoxide and methanol in $\mathrm{DMF}^{29}$ gave the corresponding methyl carboxylate 24 in $32 \%$ yield. The remaining four steps for the synthesis of desired $\mathbf{2 8}$ followed the above-described method for $\mathbf{2 2}$, 
Scheme 2. Synthesis of Estrogen-3-hydroxy (22) and 3-Carboxyl Derivative (28) ${ }^{a}$

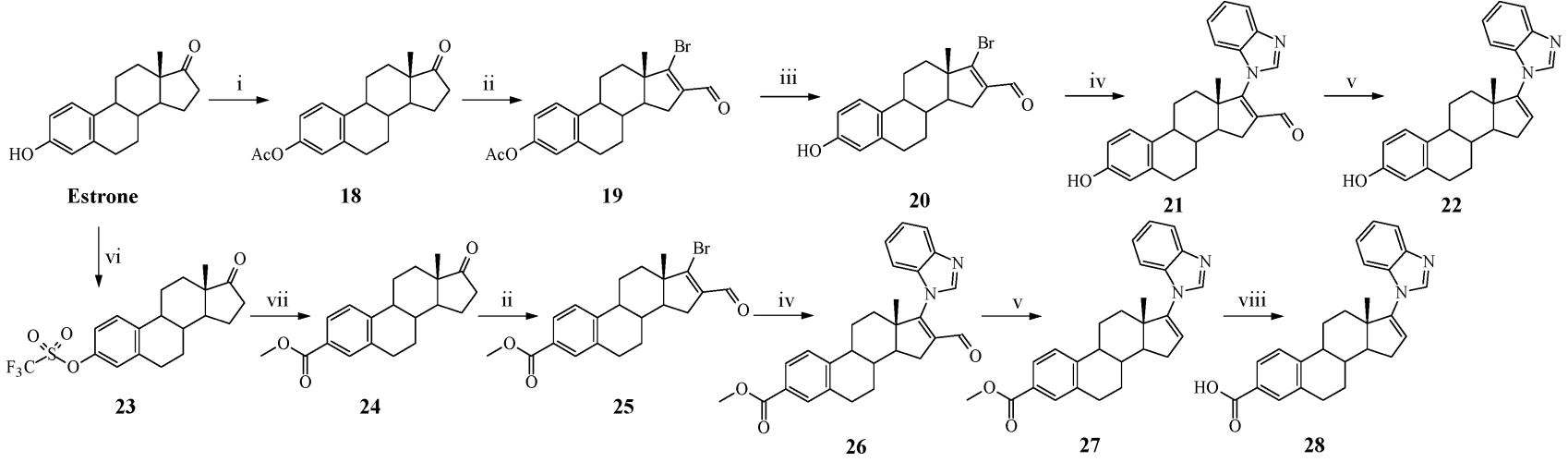

${ }^{a}$ Reagents and conditions: (i) pyridine, acetic anhydride, rt, 12 h, (ii) $\mathrm{PBr}_{3}, \mathrm{DMF}, \mathrm{CHCl}_{3}$, reflux, $5 \mathrm{~h}$; (iii) ethanol, 10\% ethanolic-KOH, rt, $12 \mathrm{~h}$; (iv) BzIm, $\mathrm{K}_{2} \mathrm{CO}_{3}$, DMF, $80{ }^{\circ} \mathrm{C}, 1-5 \mathrm{~h}$; (v) benzonitrile, $10 \% \mathrm{Pd} / \mathrm{C}, 185{ }^{\circ} \mathrm{C}, 12 \mathrm{~h}$; (vi) triflic anhydride, TEA, DCM, $0{ }^{\circ} \mathrm{C}, 1 \mathrm{~h}$; (vii) palladium(II) acetate, dppp, TEA, MeOH, DMF, carbon monoxide, $0{ }^{\circ} \mathrm{C}, 9 \mathrm{~h}$; (viii) $\mathrm{MeOH}, 10 \%$ methanolic-KOH, reflux, $2 \mathrm{~h}$.
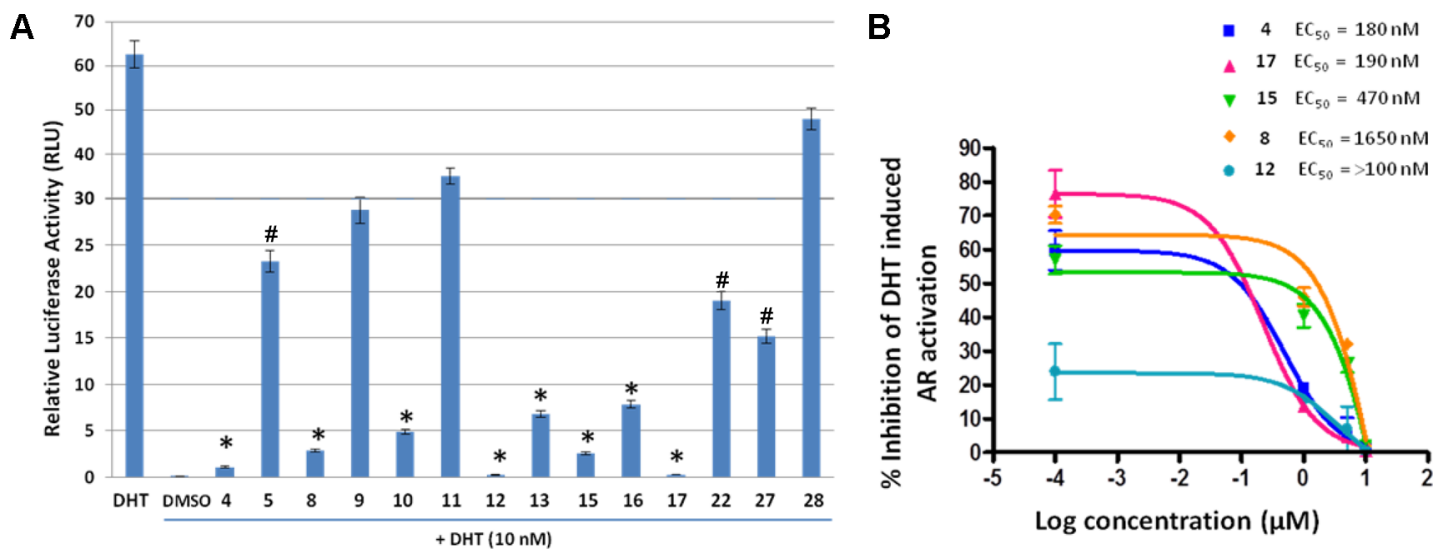

Figure 2. (A) Effects of compounds at $10 \mu \mathrm{M}$ on dihydrotestosterone (DHT)-stimulated transcription of AR. LNCaP cells were transfected with the AAR2 reporter construct + the Renilla luciferase reporting vector pRL-null and treated with novel compounds for $24 \mathrm{~h}$ in the presence of $10 \mathrm{nM}$ dihydrotestosterone (DHT). Control, baseline activity without androgen stimulation. Androgen-stimulated luciferase activity (luminescence) was measured in a Victor 1420 plate reader. The results are presented as the fold induction (i.e., the relative luciferase activity of the treated cells divided by that of the control) normalized to that of the Renilla luciferase activity. ${ }^{*}, P<0.01$; ${ }^{\#}, P<0.05$ compared with DHT treated cells. (B) Inhibitory effects of ARDAs/MDV3100 on DHT induced AR transcriptional activity in LNCaP cells. $\mathrm{EC}_{50}=$ the concentration of inhibitor (ARDAs/ MDV3100) required to inhibit the DHT-induced AR transcriptional activity by $50 \%$. $\mathrm{EC}_{50}$ values of the compounds were determined from doseresponse curves. Points, mean of replicates from three independent experiments; bars, SE. Solid line, best-fit sigmoidal dose response (variable slope).

involving three intermediate steps: formation of 16-formyl-17bromo derivative 25 (52\%) by Vilsmeier-Haack reaction, then C-17 BzIm condensation to give 26 (95\%), followed by Pd catalyzed 16-deformylation to give 27 (57\%) and finally basic hydrolysis of methyl ester group to obtain the desired compound $\mathbf{2 8}$ in $93 \%$ yield.

Structural integrity of all the compounds in the study were characterized and confirmed by ${ }^{1} \mathrm{H}$ and ${ }^{13} \mathrm{C}$ NMR and HRMS spectroscopy. Purity of the all the compounds used for biological studies are analyzed by UPLC method and are $>93 \%$ pure (see Supporting Information). Synthesis and purity check for the compounds 6-7 and 14 was reported previously. $^{22}$

To determine whether our new compounds modulate f-AR transcriptional activation, we performed a luciferase experiment utilizing LNCaP cells dual-transfected with the probasin luciferase reporter construct AAR2-luc and the Renilla luciferase reporting vector pRL-null as we previously described ${ }^{22,27}$ and reported in the Supporting Information. As shown in Figure $2 \mathrm{~A}$, luciferase expression was significantly increased after $10 \mathrm{nM}$
DHT treatment for $24 \mathrm{~h}$. The ability of the novel compounds (10 $\mu \mathrm{M}$, each) to modulate DHT-induced AR transactivation was assessed, using enzalutamide (4) and galeterone (5) as positive controls. Gratifyingly, nine of the 12 new compounds tested were more potent than galeterone and compounds $\mathbf{1 2}$ and 17 were equipotent to enzalutamide. The order of potency for the new analogues was 12, $17>8,15>10>13>16>27$ $>22>9,11>28$. Based on these results, we selected the top four compounds and determined the effective concentrations that caused 50\% inhibition of DHT-induced AR transactivation $\left(\mathrm{EC}_{50}\right.$ values) from dose-response curves (Figure $2 \mathrm{~B}$ ).

As expected, these compounds exhibited impressive $\mathrm{EC}_{50}$ values ranging from $<100$ to $1650 \mathrm{nM}$. The $\mathrm{EC}_{50}$ of compound 17 (190 nM) was comparable to that of enzalutamide (180 $\mathrm{nM})$, while that of compound $\mathbf{1 2}(<100 \mathrm{nM}$; determined via extrapolation) was superior to enzalutamide.

To determine whether our compounds induce AR degradation, LNCaP cells were treated with each of the compounds $(5,6,8,10,12,13,15-17,27$, and 28) of interest (15 $\mu \mathrm{M}$ each) for $24 \mathrm{~h}$, followed by Western blotting analysis. 

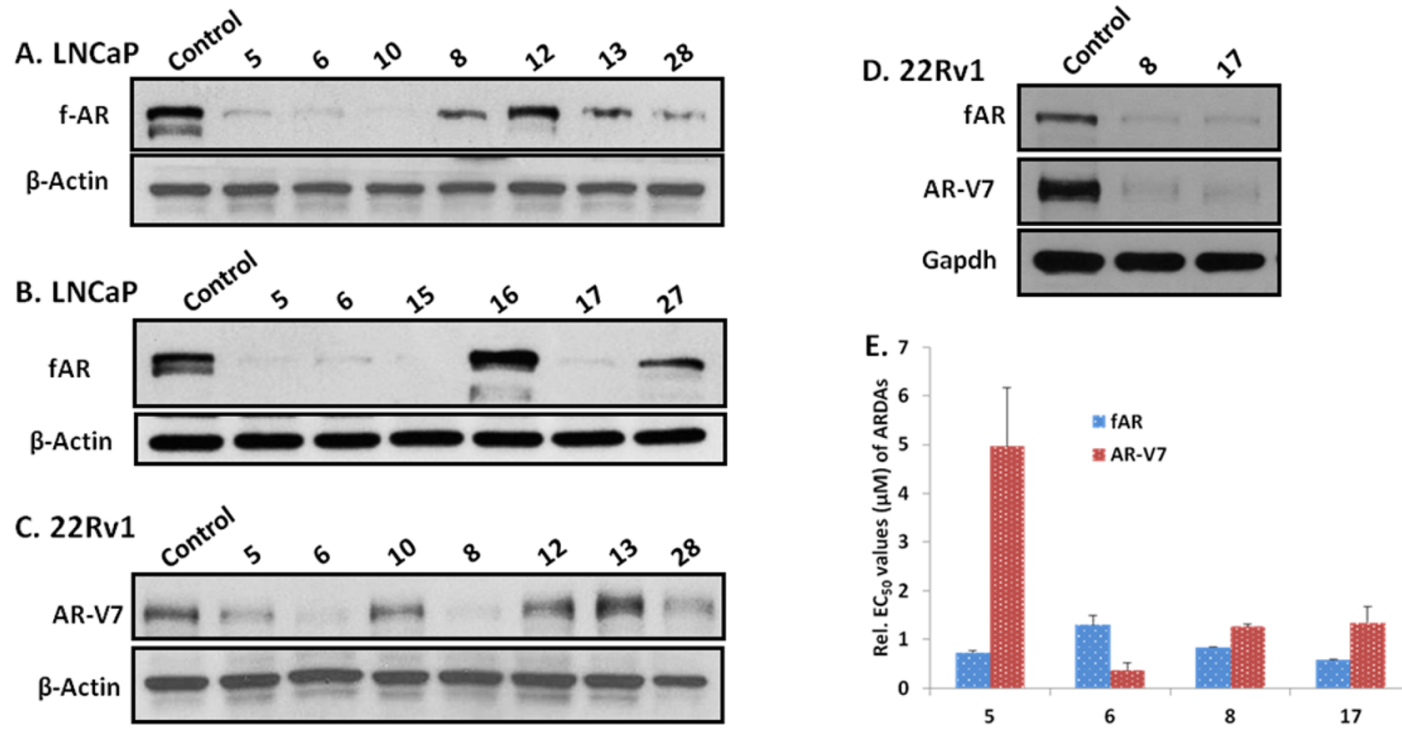

Figure 3. (A-D) Differential effect of compounds on suppressing AR expression in LNCaP and CWR22Rv1 prostate cancer cells: Western blot analysis of f-AR/AR-V7 expression in LNCaP or CWR22Rv1 cells treated with various compounds. Cells were exposed to individual compounds (15 $\mu \mathrm{M}$ ) for $24 \mathrm{~h}$, and the protein lysates were subjected to Western blot analysis. (E) $\mathrm{EC}_{50}$ values (for fAR and AR-V7) for compounds were determined from dose-response curves following compound treatments $(0 \rightarrow 7.5 \mu \mathrm{M})$ of CWR22Rv1 cells for $72 \mathrm{~h}$ followed by Western blot analysis of lysates.

As depicted in Figure $3 \mathrm{~A}, \mathrm{~B}$, most of the new compounds significantly caused AR degradation in LNCaP cells, comparable to or better than galeterone (5). We note that two compounds 12 and 16 were ineffective. It is also unclear why compound 28 caused significant AR degradation when it showed no effect on inhibition of AR transactivation as depicted in Figure 2A.

Based on our previous reports, which show that AR-Vs drive the progression of CRPC, we next determined the effect of our compounds on the down-regulation of AR-V7 (also called AR3 ). As depicted in Figure 3C, we observed that compound 5 and some of our new compounds 6,8 , and 28 tested in this assay (CWR22Rv1, prostate cancer cell line) caused significant down-regulation AR-V7. Figure 3D shows f-AR and AR-V7 depletion caused by compounds 8 and 17 . Whereas their $\mathrm{EC}_{50}$ values for f-AR are similar, compounds 6, 8, and 17 exhibited $>4$-fold increased efficacy in AR-V7 degradation activity as compared to galeterone (5) (Figure $3 \mathrm{E}$ ).

In response to some concerns of an astute reviewer, we note the following: (i) most of the AR biology studies reported here were conducted in LNCaP prostate cancer cells (expressing T877A mutant AR-FL), the dominant model system in the field that is used widely to study the general biology of $A R$, to screen for novel AR antagonists; ${ }^{30,31}$ (ii) we did not conduct AR ligand binding studies, based on our previous findings that this class of compounds does not have to bind to the AR ligand binding domain to cause modulation/degradation of AR. It is important to note that this class of compounds also causes degradation of $\mathrm{AR}$ splice variants that are devoid of the $\mathrm{LBD}^{22,25}$ (iii) for the compounds tested (see Figure 2A), agonistic activities were not observed; (iv) we have previously reported on the selectivity of galeterone (5) and compound 6, where we clearly showed that these AR degrading agents do not affect other nuclear receptors, ${ }^{25}$ which is likely to be the case with these related new analogues.

Since these compounds are analogues of galeterone (5), we evaluated their ability to inhibit CYP17 enzyme (Table 1). As
Table 1. IC $_{50}$ of Select Compounds for Inhibition of CYP17 (17 $\alpha$-Hydroxylase Activity) and GI $_{50}$ Values of Novel ARDA Compounds

\begin{tabular}{|c|c|c|c|}
\hline \multirow[b]{2}{*}{ compd } & \multirow{2}{*}{$\frac{\mathrm{IC}_{50}(\mu \mathrm{M})^{a}}{\mathrm{CYP} 17}$} & \multicolumn{2}{|c|}{$\mathrm{GI}_{50}$ values $(\mu \mathrm{M})^{b}$} \\
\hline & & $\mathrm{LNCaP}$ & CWR22Rv1 \\
\hline 8 & $>15$ & 2.45 & 3.24 \\
\hline 9 & & 4.26 & 0.81 \\
\hline 10 & 39 & 8.71 & 7.50 \\
\hline 11 & & 5.12 & 1.2 \\
\hline 12 & & 9.57 & 7.52 \\
\hline 13 & & & \\
\hline 15 & & 6.61 & 12.30 \\
\hline 16 & & 8.91 & 9.88 \\
\hline 17 & 0.480 & 1.64 & 2.54 \\
\hline 22 & 25.9 & 3.89 & 0.50 \\
\hline 27 & $>15$ & 6.91 & 8.74 \\
\hline 28 & & & \\
\hline \multicolumn{4}{|c|}{ for comparison } \\
\hline 1 & 0.048 & & \\
\hline 4 & & 4.85 & \\
\hline 5 & 0.140 & 3.93 & 8.91 \\
\hline
\end{tabular}

${ }^{a} \mathrm{IC}_{50}$ value is the concentration of inhibitor that inhibits the CYP17 enzyme activity by $50 \%$ each in duplicate. $\mathrm{IC}_{50}$ values were each determined from dose-response curve. ${ }^{b}$ The $\mathrm{GI}_{50}$ were determined from dose-response curves (by nonlinear regression analysis using GraphPad Prism) compiled from at least three independent experiments using LNCaP cells, SEM $<10 \%$, and represents the compound concentration required to inhibit cell growth by $50 \%$. Blank cells $=$ not tested.

expected, (except for $17, \mathrm{IC}_{50}=0.48 \mu \mathrm{M}$ ) the compounds were weak inhibitors of CYP17 $\left(\mathrm{IC}_{50}=2.59\right.$ to $\left.>15 \mu \mathrm{M}\right)$, buttressing established SAR data for potent steroidal CYP17 inhibitors. ${ }^{22}$

Finally, we assessed the antiproliferative activities of our novel compounds in two human prostate cancer cell lines (LNCaP and CWR22Rv1). The inhibitory concentrations that caused $50 \%$ growth inhibition of cell proliferation $\left(\mathrm{GI}_{50}\right.$ values) 
were determined from dose-response curves using MTT assays as we have previously described, ${ }^{22}$ presented in Table 1. Although there is a modest correlation between the antiproliferative activities $\mathrm{GI}_{50}$ values and inhibition of ARtransactivations, AR degrading activities, compounds 8, 9, 11, 17, and 22, are 2.4- (for $L N C a P$ ) to 18-fold (for CWR22Rv1) more potent than lead compound $\mathbf{5}$, representing a significant improvement. Their full potential may become evident following comparative in vivo antitumor efficacy assessments. It is important to note here that we have previously reported that galeterone and its analogues also inhibit the growth of PC3 and DU-145 prostate cancer cells, ${ }^{32}$ which may also be the case for these new analogues.

In conclusion, a small library of galeterone analogues was designed and synthesized with modifications of substituents at C3 and C6 and the architecture of ring A. The substituent at C 3 could be varied somewhat (see compounds 8 and 17), but a basic heterocycle seems important for bioactivity. Because the yields for these promising compounds ( 8 and 17) are low, we have embarked on new studies to develop facile and robust synthesis for these compounds. This will enable biological studies to assess their efficacies in clinically relevant models of prostate cancer, in vitro and in vivo. Importantly, the most effective compounds are predicted to be metabolically more stable (by virtues of their C-3 moieties) than compound 6, making them suitable for further development as new therapeutics against prostate cancer.

\section{ASSOCIATED CONTENT}

\section{S Supporting Information}

The Supporting Information is available free of charge on the ACS Publications website at DOI: 10.1021/acsmedchemlett.6b00137.

Synthetic experimental details, analytical and further biological data of compounds and biological assay protocols. UPLC chromatograms and high resolution mass spectral data for final compound (PDF)

\section{AUTHOR INFORMATION}

\section{Corresponding Author}

*Phone: 410-706-6364. Fax: 410-706-0032. E-mail: vnjar@ som.umaryland.edu.

\section{Present Address}

\$(M.S.M.) Bernard J. Dunn School of Pharmacy, Shenandoah University, 45085 University Drive, Suite 202, Ashburn, Virginia 20147, United States.

\section{Funding}

This work was supported in part by a grant from NIH and NCI (RO1CA129379) and start-up funds from University of Maryland School of Medicine and the Center for Biomolecular Therapeutics (CBT), and Marlene Stewart Greenbaum Cancer Center (Philanthropic Funds), Baltimore, USA to V.C.O.N. A.K.K.-A. was supported in part by University of Maryland School of Medicine Toxicology Program.

\section{Notes}

The authors declare the following competing financial interest(s): V.C.O.N. is the lead inventor of galeterone and new analogues, patents, and technologies thereof owned by the University of Maryland, Baltimore, and licensed to Tokai Pharmaceuticals, Inc. A.K.K.-A. and P.P. are co-inventors of some related compounds. A patent application to protect these novel compounds has been filed.

\section{ABBREVIATIONS}

$\mathrm{AR}$, androgen receptor; $\mathrm{ARD}, \mathrm{AR}$ down-regulation; $\mathrm{ARDAs}$, AR down-regulating agents; CRPC, castration resistant prostate cancer; gal, galeterone; $\mathrm{GI}_{50}$, compound concentration required to inhibit cell growth by $50 \%$; $\mathrm{IC}_{50}$, compound concentration required to inhibit cell growth by 50\%; MTT, 3-(4,5dimethylthiazole-2-yl)-2,5-diphenyl-2H-tetrazolium bromide; PC, prostate cancer; Pd, palladium; TEA, triethylamine; TLC, thin layer chromatography

\section{REFERENCES}

(1) Siegel, R. L.; Miller, K. D.; Jemal, A. Cancer statistics, 2015. CaCancer J. Clin. 2015, 65, 5.

(2) Vasaitis, T. S.; Bruno, R. D.; Njar, V. C. CYP17 inhibitors for prostate cancer therapy. J. Steroid Biochem. Mol. Biol. 2011, 125, 23.

(3) Vasaitis, T. S.; Njar, V. C. Novel, potent anti-androgens of therapeutic potential: recent advances and promising developments. Future Med. Chem. 2010, 2, 667.

(4) Bryce, A.; Ryan, C. J. Development and clinical utility of abiraterone acetate as an androgen synthesis inhibitor. Clin. Pharmacol. Ther. 2012, 91, 101.

(5) Chen, Y.; Clegg, N. J.; Scher, H. I. Anti-androgens and androgendepleting therapies in prostate cancer: new agents for an established target. Lancet Oncol. 2009, 10, 981.

(6) Agoulnik, I. U.; Weigel, N. L. Androgen receptor action in hormone-dependent and recurrent prostate cancer. J. Cell. Biochem. 2006, 99, 362.

(7) Loblaw, D. A.; Virgo, K. S.; Nam, R.; Somerfield, M. R.; BenJosef, E.; Mendelson, D. S.; Middleton, R.; Sharp, S. A.; Smith, T. J.; Talcott, J.; Taplin, M.; Vogelzang, N. J.; Wade, J. L.; Bennett, C. L.; Scher, H. I.; Oncology, A. S. o. C.. Initial hormonal management of androgen-sensitive metastatic, recurrent, or progressive prostate cancer: 2006 update of an American Society of Clinical Oncology practice guideline. J. Clin. Oncol. 2007, 25, 1596.

(8) Knudsen, K. E.; Penning, T. M. Partners in crime: deregulation of $\mathrm{AR}$ activity and androgen synthesis in prostate cancer. Trends Endocrinol. Metab. 2010, 21, 315.

(9) Shafi, A. A.; Cox, M. B.; Weigel, N. L. Androgen receptor splice variants are resistant to inhibitors of $\mathrm{Hsp} 90$ and FKBP52, which alter androgen receptor activity and expression. Steroids 2013, 78, 548 .

(10) Dehm, S. M.; Schmidt, L. J.; Heemers, H. V.; Vessella, R. L.; Tindall, D. J. Splicing of a novel androgen receptor exon generates a constitutively active androgen receptor that mediates prostate cancer therapy resistance. Cancer Res. 2008, 68, 5469.

(11) Li, Y.; Alsagabi, M.; Fan, D.; Bova, G. S.; Tewfik, A. H.; Dehm, S. M. Intragenic rearrangement and altered RNA splicing of the androgen receptor in a cell-based model of prostate cancer progression. Cancer Res. 2011, 71, 2108.

(12) Hu, R.; Dunn, T. A.; Wei, S.; Isharwal, S.; Veltri, R. W.; Humphreys, E.; Han, M.; Partin, A. W.; Vessella, R. L.; Isaacs, W. B.; Bova, G. S.; Luo, J. Ligand-independent androgen receptor variants derived from splicing of cryptic exons signify hormone-refractory prostate cancer. Cancer Res. 2009, 69, 16.

(13) Sun, S.; Sprenger, C. C.; Vessella, R. L.; Haugk, K.; Soriano, K.; Mostaghel, E. A.; Page, S. T.; Coleman, I. M.; Nguyen, H. M.; Sun, H.; Nelson, P. S.; Plymate, S. R. Castration resistance in human prostate cancer is conferred by a frequently occurring androgen receptor splice variant. J. Clin. Invest. 2010, 120, 2715.

(14) Guo, Z.; Yang, X.; Sun, F.; Jiang, R.; Linn, D. E.; Chen, H.; Kong, X.; Melamed, J.; Tepper, C. G.; Kung, H. J.; Brodie, A. M.; Edwards, J.; Qiu, Y. A novel androgen receptor splice variant is upregulated during prostate cancer progression and promotes androgen depletion-resistant growth. Cancer Res. 2009, 69, 2305. 
(15) Guo, Z.; Qiu, Y. A new trick of an old molecule: androgen receptor splice variants taking the stage?! Int. J. Biol. Sci. 2011, 7, 815. (16) Antonarakis, E. S.; Lu, C.; Wang, H.; Luber, B.; Nakazawa, M.; Roeser, J. C.; Chen, Y.; Mohammad, T. A.; Chen, Y.; Fedor, H. L.; Lotan, T. L.; Zheng, Q.; De Marzo, A. M.; Isaacs, J. T.; Isaacs, W. B.; Nadal, R.; Paller, C. J.; Denmeade, S. R.; Carducci, M. A.; Eisenberger, M. A.; Luo, J. AR-V7 and resistance to enzalutamide and abiraterone in prostate cancer. N. Engl. J. Med. 2014, 371, 1028.

(17) Antonarakis, E. S.; Nakazawa, M.; Luo, J. Resistance to androgen-pathway drugs in prostate cancer. N. Engl. J. Med. 2014, 371, 2233.

(18) Li, Y.; Chan, S. C.; Brand, L. J.; Hwang, T. H.; Silverstein, K. A.; Dehm, S. M. Androgen receptor splice variants mediate enzalutamide resistance in castration-resistant prostate cancer cell lines. Cancer Res. 2013, 73, 483.

(19) Mostaghel, E. A.; Marck, B. T.; Plymate, S. R.; Vessella, R. L.; Balk, S.; Matsumoto, A. M.; Nelson, P. S.; Montgomery, R. B. Resistance to CYP17A1 inhibition with abiraterone in castrationresistant prostate cancer: induction of steroidogenesis and androgen receptor splice variants. Clin. Cancer Res. 2011, 17, 5913.

(20) Schrader, A. J.; Schrader, M. G.; Cronauer, M. V. Words of wisdom. Re: androgen receptor splice variants mediate enzalutamide resistance in castration-resistant prostate cancer cell lines. Eur. Urol. 2013, 64, 169.

(21) Njar, V. C.; Brodie, A. M. Discovery and development of Galeterone (TOK-001 or VN/124-1) for the treatment of all stages of prostate cancer. J. Med. Chem. 2015, 58, 2077.

(22) Purushottamachar, P.; Godbole, A. M.; Gediya, L. K.; Martin, M. S.; Vasaitis, T. S.; Kwegyir-Afful, A. K.; Ramalingam, S.; AtesAlagoz, Z.; Njar, V. C. Systematic structure modifications of multitarget prostate cancer drug candidate galeterone to produce novel androgen receptor down-regulating agents as an approach to treatment of advanced prostate cancer. J. Med. Chem. 2013, 56, 4880.

(23) Bruno, R. D.; Vasaitis, T. S.; Gediya, L. K.; Purushottamachar, P.; Godbole, A. M.; Ates-Alagoz, Z.; Brodie, A. M.; Njar, V. C. Synthesis and biological evaluations of putative metabolically stable analogs of $\mathrm{VN} / 124-1$ (TOK-001): head to head anti-tumor efficacy evaluation of VN/124-1 (TOK-001) and abiraterone in LAPC-4 human prostate cancer xenograft model. Steroids 2011, 76, 1268.

(24) Vasaitis, T.; Belosay, A.; Schayowitz, A.; Khandelwal, A.; Chopra, P.; Gediya, L. K.; Guo, Z.; Fang, H. B.; Njar, V. C.; Brodie, A. $\mathrm{M}$. Androgen receptor inactivation contributes to antitumor efficacy of 17 alpha\}-hydroxylase/17,20-lyase inhibitor 3beta-hydroxy-17-(1Hbenzimidazole-1-yl)androsta-5,16-diene in prostate cancer. Mol. Cancer Ther. 2008, 7, 2348.

(25) Kwegyir-Afful, A. K.; Ramalingam, S.; Purushottamachar, P.; Ramamurthy, V. P.; Njar, V. C. Galeterone and VNPT55 induce proteasomal degradation of AR/AR-V7, induce significant apoptosis via cytochrome $c$ release and suppress growth of castration resistant prostate cancer xenografts in vivo. Oncotarget 2015, 6, 27440.

(26) Nahar, L.; Turner, A. B.; Sarker, S. D. Convenient synthesis of monomeric steroids from steroidal oxalate dimers using flash vacuum pyrolysis (FVP). Turk. J. Chem. 2010, 34, 359.

(27) Handratta, V. D.; Vasaitis, T. S.; Njar, V. C.; Gediya, L. K.; Kataria, R.; Chopra, P.; Newman, D., Jr.; Farquhar, R.; Guo, Z.; Qiu, Y.; Brodie, A. M. Novel C-17-heteroaryl steroidal CYP17 inhibitors/ antiandrogens: synthesis, in vitro biological activity, pharmacokinetics, and antitumor activity in the LAPC4 human prostate cancer xenograft model. J. Med. Chem. 2005, 48, 2972.

(28) Furuya, T.; Strom, A. E.; Ritter, T. Silver-mediated fluorination of functionalized aryl stannanes. J. Am. Chem. Soc. 2009, 131, 1662.

(29) Li, P. K.; Pillai, R.; Dibbelt, L. Estrone sulfate analogs as estrone sulfatase inhibitors. Steroids 1995, 60, 299.

(30) Watson, P. A.; Arora, V. K.; Sawyers, C. L. Emerging mechanisms of resistance to androgen receptor inhibitors in prostate cancer. Nat. Rev. Cancer 2015, 15, 701.

(31) Wu, H. C.; Hsieh, J. T.; Gleave, M. E.; Brown, N. M.; Pathak, S.; Chung, L. W. Derivation of androgen-independent human LNCaP prostatic cancer cell sublines: role of bone stromal cells. Int. J. Cancer 1994, 57, 406.

(32) Bruno, R. D.; Gover, T. D.; Burger, A. M.; Brodie, A. M.; Njar, V. C. 17alpha-Hydroxylase/17,20 lyase inhibitor VN/124-1 inhibits growth of androgen-independent prostate cancer cells via induction of the endoplasmic reticulum stress response. Mol. Cancer Ther. 2008, 7, 2828. 